\title{
GRANITÓIDES COM EPIDOTO MAGMÁTICO DA PROVÍNCIA BORBOREMA, NE DO BRASIL E DAS SERRAS PAMPEANAS, NW DA ARGENTINA
}

\author{
A.N.Sial ${ }^{1}$, A.J.Toselli ${ }^{2}$, J.Saavedra ${ }^{3}$, V.P.Ferreira ${ }^{1}$, J.Rossi de Toselli $^{2}$, A.E.Fallick ${ }^{4}$
}

\begin{abstract}
Granitóides com epidoto magmático (Epm) na América do Sul são observados em cinco cinturões de dobramentos no NE do Brasil (Seridó-CS, CachoeirinhaSalgueiro-CCS, Riacho do Pontal CRP, Pajeú-Paraíba- CPP e no domínio Macururé do cinturão Sergipano-MS; Sial, 1990; Sial et al., 1995) e nas Serras Pampeanas do Paleozóico Inferior (ciclo Famatiniano) no NW da Argentina (cinturão plutônico Famatina-Los Llanos-FLL e ao longo da megafratura Tafi-MFT, separados por um cinturão de cordierita granitos) (Toselli et al., 1989; Saavedra et al., 1992; Sial et al., 1995). Além disso, granitóides com Epm ocorrem no batólito do norte da Patagônia, em Aysen, Chile (F. Hervé, comun. escrita, 1996). No Brasil esses granitóides são essencialmente metaluminosos, enquanto que na Argentina são distintamente peraluminosos (MFT) ou metaluminosos (FLL). São essencialmente cálcioalcalinos ou trondhjemíticos (e.g. Galliski et al., 1990), embora membros toléticos estejam presentes na Argentina (por ex. Cerro Toro e San Agustin) e shoshoníticos no Brasil (por ex. Teixeira). No total, mais de cinqüenta granitóides com Epm foram estudados. Eles guardam semelhanças, mas divergências em mineralogia, química ou nivel de posicionamento na crosta, apontam para diferenças em sua petrogênese ou evolução magmática dos grupos identificados.

Os granitóides estudados na Argentina são tonalitos a granitos, com qz monzonitos e qz dioritos subordinados. Alguns são granitóides a duas micas, com granada, e neles, Epm ocorre como fase intersticial tardia ou está incluso em outros minerais (ex. moscovita), ou associado à reabsorção de hornblenda (Toselli et al., 1989). No NE do Brasil os plútons são tonalitos a granodioritos, comumente com enclaves $\mathrm{qz}$ dioríticos microgranulares. Epm é observado em quatro relações texturais (Sial, 1990): incluso em plagioclásio; com núcleo de allanita euedral; circundado por biotita; ou ao longo dos bordos de hornblenda em contato com plagioclásio.

A maior parte dos granitóides com Epm no NE do Brasil intrudiram rochas de grau metamórfico intermediário. No entanto, aqueles nos cinturões CCS e CRP intrudiram metaturbiditos de baixo grau (Sial, 1990), localmente desenvolvendo incomuns auréolas térmicas com cianita (Caby \& Sial, 1996), uma vez que intrudiram uma crosta fria, \& 6 kb de pressão (estimada pela barometria do Al na hornblenda; calibração de Schmidt, 1992). Na Argentina, em tonalitos (por ex. Cerro Toro) que intrudiram sin-tectonicamente gnaisses e migmatitos com cordierita e sillimanita, $\mathrm{Al} \mathrm{em} \mathrm{hbl} \mathrm{indicam} \mathrm{pressões} \mathrm{entre} 6$ e $8 \mathrm{~kb}$, embora outros plútons foram claramente posicionados a profundidades mais baixas. A presença de moscovita nos granitos
\end{abstract}

\footnotetext{
${ }^{1}$ Lab. Núcleo de Estudos de Granitos, DG, Universidade Federal de Pernambuco.

${ }^{2}$ Instituto Sup. Correl. Geologica, UNT, Tucuman, Argentina.

${ }^{3}$ IRNA, CSIC, Salamanca, Espanha.

${ }^{4}$ Scottish Universities Res. \& Reactor Centre, East Kilbride, Glasgow, Escócia.
} 
Famatinianos sugere que epidoto cristalizou direto do magma a $\mathrm{P}>3 \mathrm{~kb}$, mas a $\mathrm{P}<6 \mathrm{~kb}$, como determinado nos plútons Cerro Blanco $(4,7 \mathrm{~kb})$ e Paganzo $(5,7 \mathrm{~kb})$, pelo barômetro da hornblenda. Nos granitos Pampeanos, epidoto cristalizou-se diretamente do magma a $2<<\mathrm{P}<<$ $8 \mathrm{~kb}$ (Saavedra, 1987). Em contraste com esses resultados, plútons com cordierita de baixa profundidade de posicionamento (ex. Velasco, Capillitas, Mazan) ocorrem a uma curta distância dos granitóides com Epm.

Isócrona $\mathrm{Rb}-\mathrm{Sr}$, obtida nos granodioritos hospedeiros e seus enclaves máficos microgranulares do CCS, indica uma idade de $620 \mathrm{Ma}$, com $\mathrm{Ri}=0,70598$ e uma regressão altamente linear, indicando que enclaves e magma hospedeiro são cogenéticos ou se equilibraram isotopicamente durante o resfriamento. Em termos de geoquímica isotópica, plútons equivalentes no MS (ex. plúton de Coronel João Sá), mostram razões iniciais mais altas $(0,7080-0,7100$; McReath et al., 1993). Plútons com Epm na Argentina não mostram um comportamento único em termos de isótopos de $\mathrm{Sr}$. Os plútons peraluminosos mostram baixas razões iniciais $(\sim 0,7050)$ e os metaluminosos mostram valores mais altos $(\sim 0,7100)$. Valores de $\mathrm{MLNd}$, calculados para 0,5 $\mathrm{Ga}$, variam de $-1,0$ a $-4,0$ nos granitóides peraluminosos de Tafi del Valle e Cafayate nas Serras Pampeanas (Miller et al., 1991). Valor de $\Omega 0^{18}$ de rocha total calculado a partir do valor para qz para o plúton de Cafayate é de $+9,8 \%$ osmow, um valor ligeiramente mais baixo que aqueles para os granitóides com Epm do CCS, mas mais altos que aqueles para os plútons do CS. Valores de M.Nd, calculados para $0,6 \mathrm{Ga}$, variam de $-1,0$ a $-2,0$ para os plútons com Epm do CCS (Van Schmus et al., 1995). $\Omega 0^{18}$ para esses $s$ varia de $+11 \mathrm{a}+13 \%$, enquanto que nos $\mathrm{s}$ do CS varia $\mathrm{de}+7 \mathrm{a}+10 \%$. Valores de $\mathrm{D} / \mathrm{H}$ em rocha total para granodioritos hospedeiros, enclaves máficos microgranulares e clots ricos em anfibólio do CCS têm uma variação grande, de -69 a $114 \%$ osmow (sem correlação com $\mathrm{H}_{2} \mathrm{O}$ ), extrapolando $\Omega \mathrm{D}$ para a maioria das rochas terrestres. Valores de $\Omega S^{34}$ de $+1,0$ e $+9,0 \%$ сCDT foram encontrados para os granitóides com Epm do CCS (Sial \& Ferreira, 1990), típicos para os granitos da série magnetita no Japão. O granodiorito Glória Norte no MS, que exibe características mineralógicas de granitóides do tipo I, tem alto valor de $\Omega \mathrm{O}^{18}$ (+9,6\%osmow), aproximando-se do valor limite entre granitóides dos tipos I e $\mathrm{S}$ (+10\%osmow) do cinturão Lachlan na Austrália. Clots ricos em anfibólio (CRA) nos s desse domínio mostram valores de $+7,7 \%$ osmow (Coronel João Sá) e $+9,0 \%$ osmow (Glória norte). Esses valores são mais baixos que aqueles mostrados pelos CRA's do CCS, mas são ainda mais altos que aqueles esperados para anfibolitos típicos. Eles mostram valor médio de $\Omega \mathrm{D}$ de $-85 \notin 7 \%$ (6 análises, incluindo anfibólio, biotita do núcleo e camada externa do clot, e granodiorito hospedeiro), que está dentro (ou é ligeiramente mais baixo) da variação ígnea "normal" dos valores de $\Omega$ D. Esta é uma variação consideravelmente pequena comparada com aquela mostrada pelos s do CCS.

Em conclusão, os granitóides com Epm dos cinturões Cachoeirinha-Salgueiro, Riacho do Pontal e Sergipano, no NE do Brasil, são muito semelhantes uns aos outros em termos de mineralogia e química e provavelmente derivaram de fusão de crosta oceânica intemperizada, como apoiado por assinaturas isotópicas de $\mathrm{Sr}, \mathrm{Nd}, \mathrm{S}$ e $\mathbf{O}$. Esses granitóides são granitos do tipo I de alto $\bumpeq \mathrm{O}^{18}$, e antecipa-se valores similares de $\Omega \mathrm{O}^{18} \mathrm{em}$ granitóides equivalentes no MS. Não há um modelo petrogenético único para os granitóides com Epm nos cinturões Pajeú-Paraíba e Seridó. Na Argentina, a presença de fácies contendo moscovita e granada em um mesmo, com epidoto e titanita, o caráter peraluminoso, baixa razão inicial de $\mathrm{Sr}$ na suíte da megafratura de Tafi, versus razão inicial alta de Sr no cinturão plutônico metaluminoso de Famatina-Los Llanos, desafia a validade do esquema de classificação S-I-M-A para granitóides como esses em consideração. As tendências cálcio-alcalinas (tonalitos e granodioritos) e subalcalinas (qz monzonitos) podem ser explicadas pelo processo de cristalização fracionada com uma separação mais ou menos completa entre cumulatos e líquidos intercúmulos. 
Agradecimentos

Este trabalho foi parcialmente apoiado por auxilios do programa PADCT (PADCT/FINEP, conv. $\mathrm{n}^{\circ}$ 65.930.619-00) e do VITAE (proc. B-11487/3B001), os quais somos agradecidos. J.S. agradece o apoio financeiro do projeto CIl-CT920088 da Comunidade Européia. Esta é a contribuição $\mathrm{n}^{\circ} 95$ do Lab. Núcleo de Estudos de Granitos (NEG), Dept.de Geologia, UFPE.

\section{Referências Bibliográficas}

CABY, R.; SIAL, A.N. (1996) Reunion des Sciences de la Terre, 16., Orleans, SGF, p.87.

GALLISKI, M.A.; TOSSELI, A.J.; SAAVEDRA, J. (1990) Petrology and geochemistry of the Cachi hight-alumina trondhjemites, northwestern Argentina. Geological Society of America.Special Paper, v.241, p.91-100.

McREATH, I.; LAFON, J.M.; CHAVES, J.M.; CONCEIÇÃO, H. (1993) Strontium isotope and geochemical evidence for complex petrogenesis in the Coronel João intrusion, Sergipe fold belt. In: CONGRESSO BRASILEIRO DE GEOQUÍMICA, 4., Brasilia, 1993. Resumos Expandidos. Brasilia, SBGq. p.86-89.

MILLER, C.F.; PANKHURST, R.J.; RAPELA, C.W.; SAAVEDRA, J.; TOSELLI, A. (1991) Genesis de los granitoides paleozoicos peraluminosos, areas tafi del Valle y Cafayate, sierras Pampeanas, Argentina. In: CONGRESSO GEOLOGICO CHILENO, 6. Santiago, 1991. Actas. Santiago, Servicio Nacional de Geologia y Mineria/SGC. p.36-39.

SAAVEDRA, J.; TOSELLI, A.J.; TOSELLI, J.N.R.; RAPELA, C.W. (1987) Role of tectonism and fractional crystallization in the origin of lower paleozoic epidote-bearing granitoids, northwestern Argentina. Geology, v.15, n.8, p.709-713.

SAAVEDRA, J.; PELLITERO, P.E.; ROSSI, J.N.; TOSELLI, A.J. (1992) Magmatic evolution of the Cerro Toro granite, a complex Ordovician pluton of northwestern Argentina. Journal of South America Earth Sciences, v.5, n.1, p.21-32.

SCHMIDT, M.W. (1992) Amphibole composition in tonalite as a function of pressure: an experimental calibration of the al-in-hornblende barometer. Contributions to Mineralogy and Petrology, v.110, n.2-3, p.304-310.

SIAL, A.N. (1990) Epidote-bearing calc-alkalic granitoids in northeast Brazil. Revista Brasileira de Geociências, v.20, n.1-4, p.88-100.

SIAL, A.N.; FERREIRA, V.P. (1990) Granitoids in northeastern Brazil: oxygen and sulfur isotope composition and depths of emplacement. Journal South American Earth Sciences, v.3, n.2-3, p.103-112.

SIAL, A.N.; TOSELLI, A.J.; SAAVEDRA, J.; FERREIRA, V.P.; ROSSI DE TOSELLI, J.N. (1995) Magmatic epidote-bearing granitoids from NW Argentina and NE Brazil. U.S. Geological Survey Circular, n.1129, p.141-142.

TOSELLI, A.J.; ROSSI DE TOSELLI, J.N.; SAAVEDRA, J.; PELLITERO, E. (1987) Granitoids of the tafi megafracture (Sierras Pampeanas, Argentina): petrogenetic implications. Journal of South American Earth Sciences, v.2, n.2, p.199-204.

VAN SCHMUS, W.R. et al. (1995) Journal of South American Earth Sciences, v.8, p.267288. 